\title{
Effects of muscarine given into the brain of fowls
}

\author{
E. MARLEY AND T. J. SELLER*
}

Institute of Psychiatry, De Crespigny Park, London SE5

\section{Summary}

1. The effects of muscarine, given intraventricularly, in adult conscious fowls (Gallus domesticus) or microinfused into various brain regions of conscious young chicks, were tested on behaviour, electrocortical activity and respiratory rate. Its effects given intraventricularly or intravenously to anaesthetized fowls were also examined.

2. After intraventricular injection, muscarine elicited immediate behavioural and electrocortical arousal ; body temperature was unaffected. After a delay of 30-40 min, tachypnoea developed together with postural changes which included partial abduction of the wings away from the trunk, the back and tail becoming horizontal. These effects were prevented by intravenous or intraperitoneal atropine or hyoscine, but not by pempidine or methylatropine, and were potentiated by physostigmine. Hyoscine given intraventricularly or intravenously did not affect electrocortical activity.

3. Intraventricular muscarine given to anaesthetized adult fowls produced brief apnoea. On return of respiration, amplitude of respiratory excursion was diminished for about $5 \mathrm{~min}$; tachypnoea did not develop. Blood pressure also rose briefly. With larger doses of intraventricular muscarine, large amplitude electromyographic potentials developed in the dorsal neck muscles followed later by side-to-side neck movements.

4. Muscarine given intravenously to anaesthetized adult fowls, raised blood pressure and perfusion pressure in a perfused hind limb, an effect most likely due to secretion of adrenal medullary catecholamines; these pressor effects were prevented by pempidine and phenoxybenzamine. Given directly to the perfused hind limb, muscarine lowered perfusion pressure.

5. In young chicks, muscarine microinfused into the diencephalon or myelencephalon elicited intense bilateral electrocortical alerting associated with periods of alternating violent motor activity and quiescence. Microinfusion of muscarine into the telencephalon induced ipsilateral electrocortical desynchronization without affecting behaviour. These effects of muscarine were prevented by intravenous, intraperitoneal or intracerebral hyoscine, but once its effects were established could be antagonized only with difficulty ; pempidine did not prevent these effects. Microinfusions of muscarine into the brain did not affect posture, respiration or temperature. SW7.

* Present address : Department of Zoology, Imperial College, Prince Consort Road, London 


\section{Introduction}

Dale (1914) demonstrated that acetylcholine had two distinct actions, one muscarine-like, the other nicotine-like. Therefore, in analysing the action of acetylcholine, effort is made to elucidate, usually by means of selective antagonists, which of these two modes of action is responsible for the particular effect. In the series of experiments to be described, behavioural and electrocortical effects of muscarine, nicotine and choline esters, including acetylcholine, were investigated by microinfusion into the brain or by injection into the IIIrd cerebral ventricle. The central effects of muscarine were prevented by atropine or hyoscine whereas those of nicotine were abolished by large doses of nicotine or prevented by ganglion-blocking agents, such as mecamylamine or pempidine. A brief account of these findings has been published (Marley \& Seller, 1970a \& b). The present paper describes more fully the effects of muscarine; effects of other cholinomimetic drugs are to be published separately.

Although muscarine and nicotine have been applied to single neurones in the brain of non-anaesthetized preparations (Bradley, Dhawan \& Wolstencroft, 1966 ; Krnjevic \& Phillis, 1963), there is a dearth of information concerning the action of muscarine on behaviour and electrocortical activity. This lack of information almost certainly relates to scarcity of muscarine.

\section{Methods}

\section{Animals}

Adult or young Rhode Island Red pullets were used. Adults (1.75-2.25 kg) were kept at room temperature $\left(20^{\circ}-22^{\circ} \mathrm{C}\right)$. Young chicks (12-21 day old chicks, approximately $85 \mathrm{~g}$ ) were maintained at a cage temperature of $29^{\circ}-31^{\circ} \mathrm{C}$.

\section{Intraventricular and intracerebral cannulae}

Construction of intraventricular cannulae for adult fowls and intracerebral cannulae for young chicks was as described by Marley \& Stephenson (1968).

\section{Anaesthesia}

For recovery experiments, cannulae, electrodes and thermistors, were implanted under halothane anaesthesia; halothane (Fluothane, I.C.I.) was delivered from a Goldman or a Vapor vaporizer (Marley \& Payne, 1964). Otherwise, fowls were anaesthetized with chloralose $(60 \mathrm{mg} / \mathrm{kg})$ given into a wing vein.

\section{Operative procedures}

Techniques of implanting electrodes for recording cortical or electromyographic activity (Key \& Marley, 1962) and for placing a thermistor subcutaneously between the scapulae (Allen \& Marley, 1967) have been described previously. In adult fowls, cortical, electromyograph and thermistor leads were soldered to contacts of a 10-way socket (Ether Ltd.) fixed to the skull with acrylic dental cement. For young chicks, the electrodes were also attached to the skull with dental cement and were of sufficient length $(75 \mathrm{~cm})$ for the creature to move and feed freely. Methods for stereotactically implanting cannulae into the IIIrd cerebral ventricle of adult 
fowls (Grunden \& Marley, 1970) and into various sites of the young chick's brain (Marley \& Stephenson, 1970) have been described.

\section{Postoperative care}

On recovery from anaesthesia (5-20 min), chicks and fowls were returned to a draught-free recovery box maintained at the same temperature as the home cage.

\section{Experimental procedures}

Chickens were tested at least $24 \mathrm{~h}$ after implantation of cannulae and electrodes, when recovery was complete. Young chickens were used once only except for study of drug antagonism and potentiation, when experiments were performed on 2 consecutive days. In adult fowls, intraventricular injections were given at intervals of at least 1 week over several months.

About $1 \mathrm{~h}$ before testing, the young chick was placed in a soundproof, environment-controlled experimental box (Stephenson, 1969) with one-way screen and facilities for external monitoring of temperature and electrocortical activity. Adult fowls were housed in a chamber of similar but simpler design. The recording leads were connected to the input of a Kaiser electroencephalograph and a thermistor thermometer.

\section{Electrocortical activity}

Bipolar recordings of electrocortical activity were made and integrated each minute, in earlier experiments by feeding the output from the electroencephalograph into integrating motors (Ether Ltd.), and in subsequent experiments to Honeywell precision integrators with automatic print-out.

\section{Temperature}

This was recorded automatically and continuously on a thermistor thermometer (Grants).

\section{Electromyographic activity}

This was recorded on a Devices polygraph from electrodes implanted in the dorsal muscles of the neck.

\section{Respiration}

In non-anaesthetized adult fowls respiration was monitored by counting respiratory movements over $15 \mathrm{~s}$ each min, and converting to rate per minute. For fast respiratory rates, frequency of gular fluttering was counted since this coincides with that of respiration (Calder \& Schmidt-Nielsen, 1968) and was easier to count. Anaesthetized fowls were intubated, the tracheal cannula having a side-arm with adjustable screw-slip. The tracheal cannula was connected to a micromanometer and thence to a Devices polygraph. The screw-clip on the side-arm was adjusted until respiratory movements were accompanied by adequate excursions of the recording pen. This provided absolute measure of respiratory rate but only relative measure of respiratory amplitude. 


\section{Blood pressure}

In adult fowls anaesthetized with chloralose, blood pressure $(1 \mathrm{mmHg} \equiv 1.333$ mbar) was recorded continuously, from an ischiadic artery connected via a polyethylene cannula to a pressure transducer (Bell \& Howell Ltd.) and Devices pen recorder.

\section{Drug administration}

Injections into the implanted ventricular cannula were given via an injection cannula attached by a length of polyethylene tubing to a $100 \mu \mathrm{l}$ syringe, $10 \mu \mathrm{l}$ (occasionally $20 \mu \mathrm{l}$ ) being injected over $20-40$ seconds. For intracerebral infusions, the syringe was operated by a Palmer slow-infusion pump exterior to the recording chamber ; $1.0 \mu \mathrm{l}$ was infused over 0.5 minute.

\section{Perfused hind limb}

In chloralose anaesthetized fowls, heparinized blood was drawn from one ischiadic artery through silicone rubber tubing by a roller pump (Saxby, Siddiqi \& Walker, 1960) driven by a Servomex Motor Controller and collected in a reservoir of approximately $4 \mathrm{ml}$ capacity. It was then delivered at $15-20 \mathrm{ml} / \mathrm{min}$ by the roller pump into the proximal end of the ischiadic artery of the contralateral limb. The reservoir prevented transmission of changes in systemic blood pressure to the perfused limb. Perfusion and systemic pressures were measured by transducers writing on a Devices pen recorder. Flow rate was adjusted so that perfusion pressure approximated systemic blood pressure.

\section{Histology}

In some fowls, correct positioning of the IIIrd ventricle cannula was established by flow of clear cerebrospinal fluid at the time of implantation. However, it was confirmed in all fowls by injecting $20 \mu \mathrm{l}$ of indian ink on concluding the experimental studies, followed by autopsy and finding ink in the ventricular system after fixing the brain with formalin and examining sections at $25 \mu$ intervals. With young chicks, position of the microcannula was also established histologically. The brain was preserved in formalin, then stained with luxol fast blue and cresyl violet after rapid embedding in celloidin (Inman, 1968).

\section{Antagonist to agonist ratios}

In relating the ratio of antagonist to agonist in brain, after intravenous or intraperitoneal injection of antagonists, we have assumed a $5.0 \mathrm{~g}$ brain weight for a $2.0 \mathrm{~kg}$ fowl and a $1.5 \mathrm{~g}$ brain weight for a $100 \mathrm{~g}$ chick. These weights are based on those obtained for brains removed from adult and young chickens. It has also been assumed that the antagonist was distributed evenly throughout the body. The ratio is one of quantity of antagonist distributed throughout the entire brain to total dose of agonist given intraventricularly or into the brain substance and is therefore much higher than that achieved locally for the antagonist. 
Drugs

Drugs used, with molecular weights in parentheses, were atropine sulphate (694), atropine methylnitrate (366), hyoscine hydrobromide (438), mecamylamine hydrochloride (203), ( \pm )-muscarine iodide (301), nicotine base (162), pempidine tartrate (305), phenoxybenzamine hydrochloride (340) and physostigmine sulphate (648). Drugs given into the brain or ventricular system are expressed as $\mu$ mol total dose ; those administered intra-arterially, intraperitoneally or intravenously are given as $\mu \mathrm{mol} / \mathrm{kg}$.

\section{Results}

\section{Intraventricular injections}

Non-anaesthetized fowls

A total of twenty-two experiments were performed in eleven adult fowls. Intraventricular muscarine elicited characteristic and reproducible alterations in behaviour, posture, electrocortical activity and respiratory rate.

Posture and non-learnt behaviour. After muscarine, there was immediate behavioural arousal together with vertical head-jerking and increased frequency of nictitating membrane movements. These effects were obtained with a dose as small as $0.0017 \mu \mathrm{mol}$. With larger doses $(0.0067 \mu \mathrm{mol})$, in addition to the above effects

\section{Intraventricular}
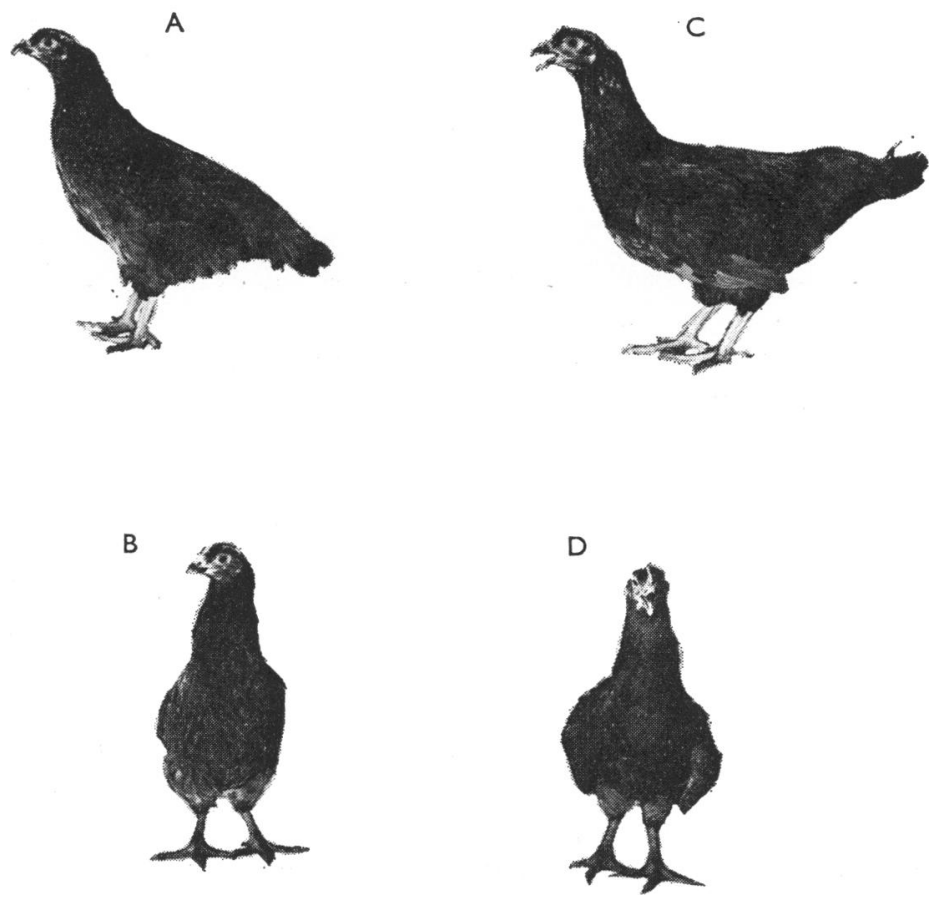

FIG. 1. Effects on posture of muscarine $(0.0067 \mu \mathrm{mol}$, intraventricularly) in an adult fowl. Photographs A and B are of controls. C and D illustrate that the back becomes horizontal after muscarine (contrast with the normal 30 to $45^{\circ}$ slope of the back in Fig. 1A), the tail is extended, the wings lowered with respect to the trunk (C) and abducted from it (D), the primary wing feathers are visible below the secondaries and the beak is open. 
and $30-40 \mathrm{~min}$ after injection, the wings, at the junction of the humeri with the scapulae, were abducted from the trunk at an angle of approximately $30^{\circ}$ ( compare Fig. 1D with 1B), the remaining part of the wings staying in the vertical plane parallel to the long axis of the body. The radius and ulna were partly extended on the humerus and the wrist abducted so that the wings were lowered with respect to the trunk (compare Fig. 1C with 1A). The primary wing feathers were separated, apparently as a consequence of wrist abduction; configuration of the body and remaining wing feathers were unaltered. The normal slope of the spine (Fig. 1A) was altered so that the back and tail became horizontal (Fig. 1C). The jaws were parted (Fig. 1C, D). These postural changes lasted for 60 to 90 minutes.

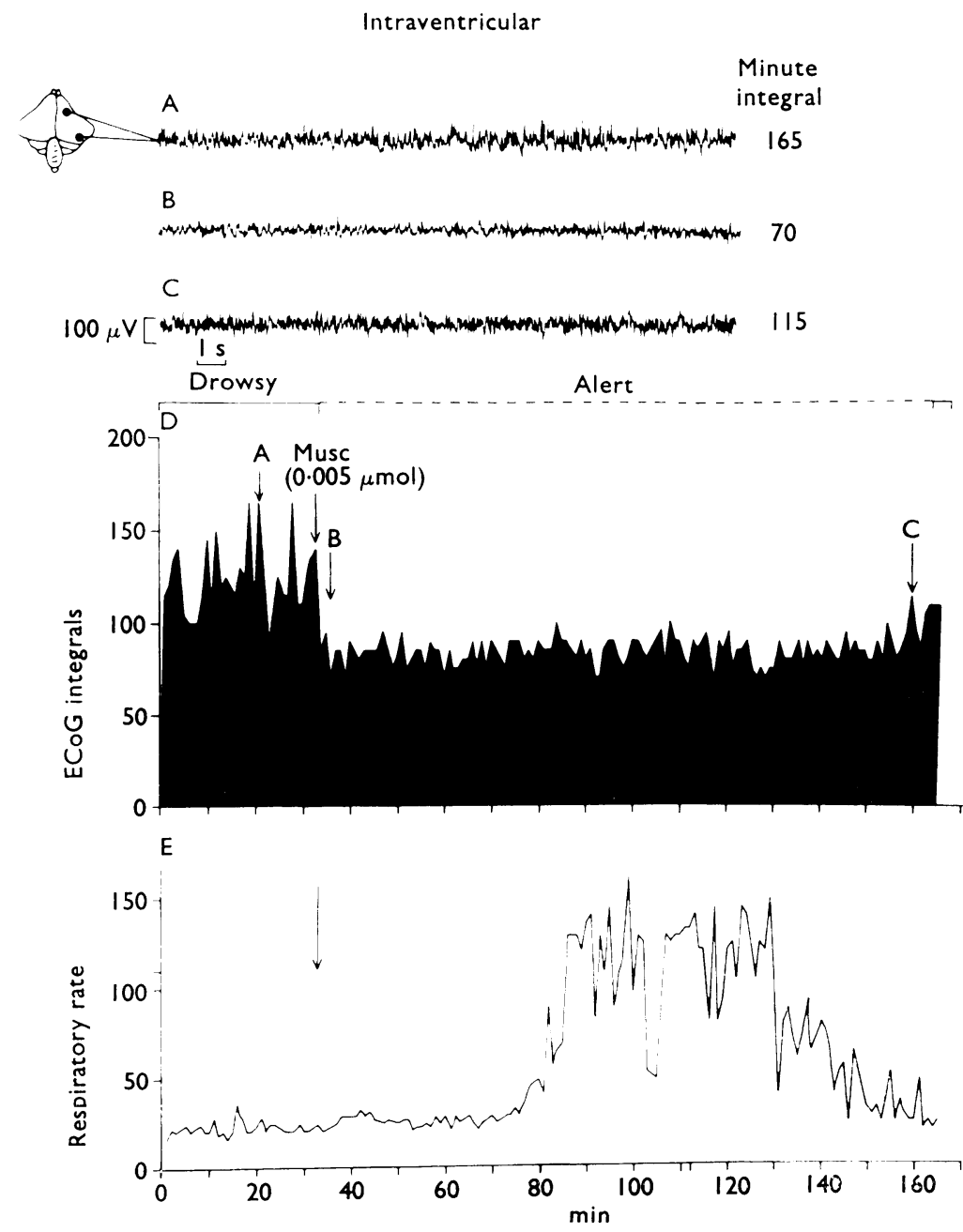

FIG. 2. Records of electrocortical activity (A-C), histogram of integrated electrocortical activity (D) and graph of respiratory rate (E) in an unanaesthetized, unrestrained adult fowl. Epochs corresponding to $\mathrm{A}, \mathrm{B}$ and $\mathrm{C}$ are indicated in the histogram and integrals for the corresponding minute of electrocortical activity are given on the right of the traces. A. Control drowsy electrocortical activity. B, Electrocortical arousal after muscarine $(0 \cdot 005$ $\mu \mathrm{mol})$. C, Return of drowsy electrocortical activity $125 \mathrm{~min}$ after muscarine. D, Reduction of electrocortical integrals accompanying electrocortical arousal, and E. considerable increase in respiratory rate $4.5 \mathrm{~min}$ after muscarine injection. 
Electrocortical activity. As shown in Fig. 2, muscarine induced electrocortical alerting. The fowl from which this figure was taken was drowsy before drug administration, electrocortical activity being of large amplitude $(75-175 \mu \mathrm{V})$, slow frequency (8-10 Hz) pattern (Fig. 2A). Behavioural and electrocortical arousal developed within $1 \mathrm{~min}$ of injecting muscarine $(0.005 \mu \mathrm{mol})$, in contrast to a delay of $30-40$ min before postural changes developed; in fowls, alert before injection, arousal was intensified. As shown in Fig. 2B, electrocortical amplitude decreased to 25-85 $\mu \mathrm{V}$ of frequency $12-30 \mathrm{~Hz}$. Electrocortical arousal was accompanied by reduction of electrocortical integrals ranging from 100-165/min before injection (Fig. 2D, arrow A) to values between $70-100 / \mathrm{min}$ (Fig. 2D, arrow B) after muscarine. Arousal, which usually lasted $60-90 \mathrm{~min}$ with muscarine $0.005 \mu \mathrm{mol}$, persisted in this fowl for $125 \mathrm{~min}$, by which time there was some return of drowsy electrocortical activity (Fig. 2C) with increase in electrocortical integrals (Fig. 2D, arrow C). Rapid onset of electrocortical arousal with muscarine, evident from reduction of electrocortical integrals, is depicted also in Figs. 3A, 4A and 5A.

Respiration. Muscarine, 0.005-0.0067 $\mu \mathrm{mol}$, increased respiratory rate (Figs. 2E, 4B, 5B), whereas a dose of $0.0017 \mu \mathrm{mol}$, which induced electrocortical arousal (Fig. 3A) did not affect respiration (Fig. 3B). As evident from Figs. 2E, 4B and 5B, there was a latency of $30-40 \mathrm{~min}$ after muscarine administration before respiratory rate increased. Once tachypnoea developed, respiratory rate remained between $120-180 / \mathrm{min}$ over the ensuing $30 \mathrm{~min}$ or so. In contrast to the rapid increase after

Intraventricular

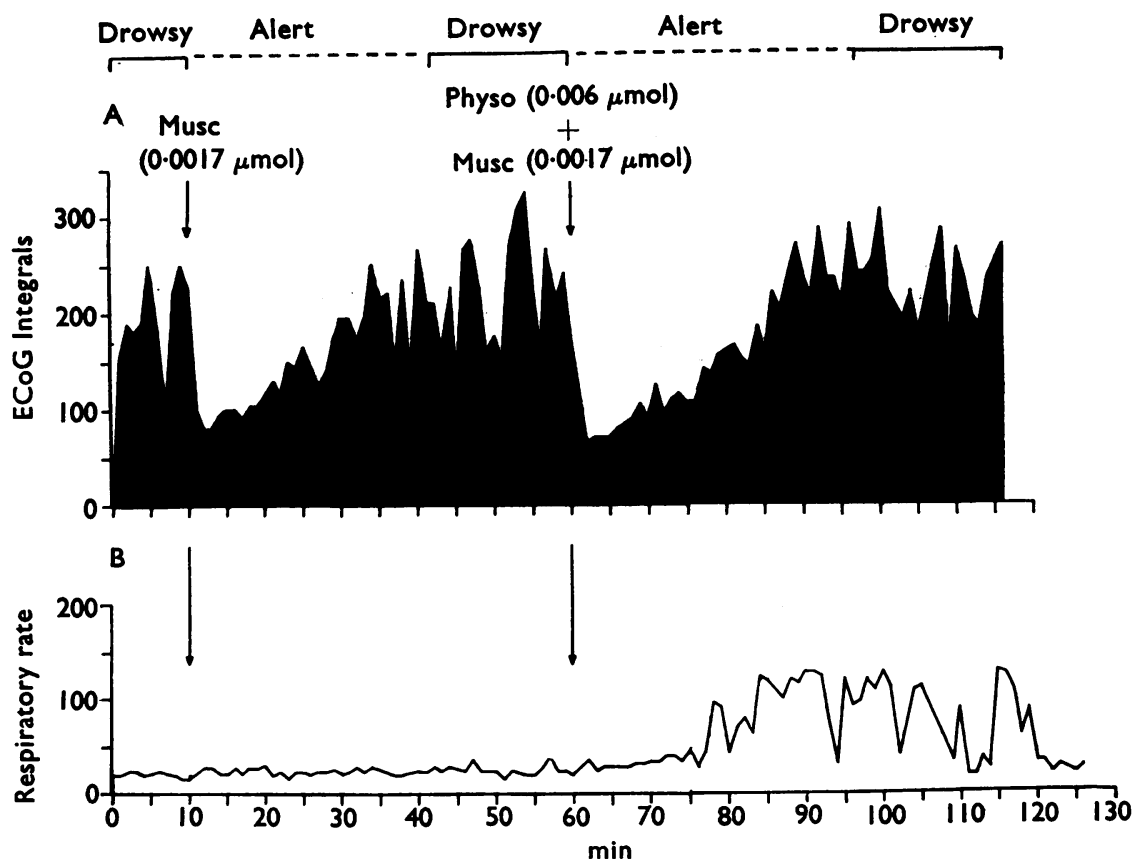

FIG. 3. Histogram of integrated electrocortical activity (A) and graph of respiratory rate (B) in an unaesthetized, unrestrained adult fowl. Muscarine $(0.0017 \mu \mathrm{mol}$, intraventricularly) elicited electrocortical arousal in the drowsy fowl associated with reduction of electrocortical integrals but was without effect on respiratory rate. In contrast, the same dose of muscarine given intraventricularly, together with physostigmine, evoked immediate and more prolonged electrocortical arousal together with longer-lasting reduction of electrocortical integrals in the drowsy fowl and increase in respiratory rate after a delay of 17 minutes. 
muscarine, respiratory rate gradually dwindled to preinjection values of between 14 and $24 / \mathrm{min}$, as the effect of muscarine abated. The onset and offset of tachypnoea coincided with those for postural changes.

Temperature. Muscarine, 0.005-0.0067 $\mu \mathrm{mol}$, did not affect the body temperature of fowls at thermoneutral temperatures $\left(20^{\circ}-22^{\circ} \mathrm{C}\right)$.

Potentiation. As shown in Fig. 3B, muscarine $(0.0017 \mu \mathrm{mol})$ did not affect respiratory rate but elicited electrocortical arousal in a previously drowsy hen, electrocortical integrals declining from a peak of $250 / \mathrm{min}$ to $82 / \mathrm{min}$ (Fig. 3A) ; behavioural arousal accompanied electrocortical alerting. Over the ensuing $25 \mathrm{~min}$ electrocortical integrals returned to about $250 / \mathrm{min}$, by which time the fowl was again drowsy. The same dose of muscarine was then injected $50 \mathrm{~min}$ after the first, but together with physostigmine $(0.006 \mu \mathrm{mol})$. In tests on other fowls, this dose of physostigmine lacked effect on respiration or posture but induced brief electrocortical alerting. In contrast to the lack of effect after muscarine alone, respiratory rate now rose to $95 /$ minute. This occurred $17 \mathrm{~min}$ after injection, in comparison with a delay of 30-40 min for larger doses of muscarine in the absence of physostigmine. Twenty-five minutes after injection, respiratory rate was $120-130 / \mathrm{min}$; tachypnoea lasted 45 minutes. Typical postural changes also developed and subsided pari passu with increase and slowing of respiratory rate. The effects on posture and respiration were compatible with potentiation of muscarine by physostigmine. Since muscarine is not hydrolysed by cholinesterases (Fraser, 1957), the results could imply the release by muscarine of acetylcholine from cholinergic neurones, and its protection from breakdown by physostigmine. Electrocortical
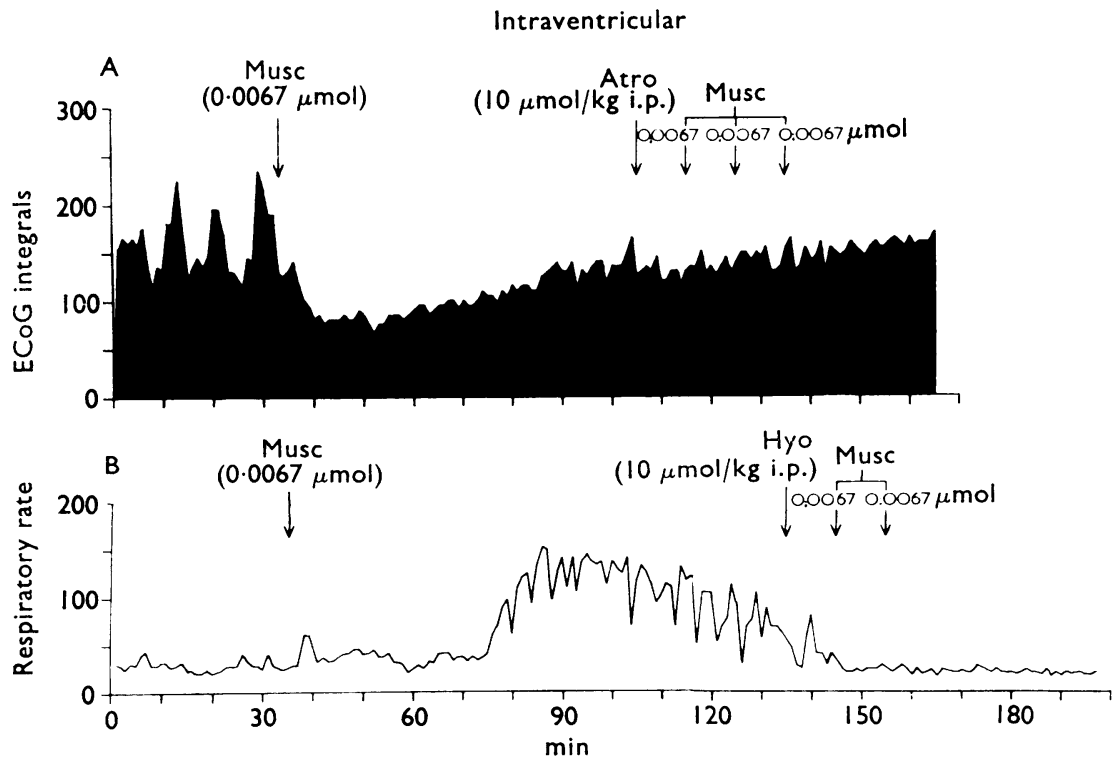

FIG. 4. Histogram of integrated electrocortical activity (A) and graph of respiratory rate (B) from two unanaesthetized, unrestrained adult fowls. As shown in A, electrocortical arousal elicited in a drowsy hen by muscarine $(0.0067 \mu \mathrm{mol}$, intraventricularly) was accompanied by reduction in electrocortical integrals, while in $B$, the same dose of muscarine, after a delay, increased respiratory rate, peak effect occurring $50 \mathrm{~min}$ after the injection. In contrast, after $10 \mu \mathrm{mol} / \mathrm{kg}$, intraperitoneally, of atropine or hyoscine respectively, three separate doses of muscarine $(0.0067 \mu \mathrm{mol}$ each) given over a $20 \mathrm{~min}$ period now had no effect on electrocortical activity or integrals, and two separate similar doses of muscarine had had no effect on respiratory rate $50 \mathrm{~min}$ after injection. 
arousal was also more marked after muscarine and physostigmine, integrals declining from $250-330 / \mathrm{min}$ to $66 / \mathrm{min}$ with gradual return to preinjection values after 30 minutes. In view of the action of physostigmine on electrocortical activity, this intensification of effect could be as much attributed to summation as to potentiation.

Antagonism. Behavioural, electrocortical and respiratory changes induced by muscarine were prevented by atropine or hyoscine. Figure 4 depicts results obtained from two fowls. In one, muscarine $(0.0067 \mu \mathrm{mol})$ induced almost immediate electrocortical arousal reflected in reduction of electrocortical integrals ranging from 110 $235 / \mathrm{min}$ in the drowsy fowl before injection to approximately $70 / \mathrm{min}$ (Fig. 4A) after muscarine. Over the subsequent $70 \mathrm{~min}$, electrocortical integrals returned to about $140 / \mathrm{min}$ during which time changes in posture and respiratory rate also developed and waned. Atropine $(10 \mu \mathrm{mol} / \mathrm{kg}$, i.p. $)$ was then injected. With the same dose of muscarine, this would give an antagonist: agonist ratio of 7.5:1 in the brain. Three intraventricular doses of muscarine, each of $0.0067 \mu \mathrm{mol}$, given over the ensuing $30 \mathrm{~min}$ now lacked effect on electrocortical activity and integrals (Fig. 4A), posture or respiration. In another fowl, muscarine $(0.0067 \mu \mathrm{mol})$ produced tachypnoea of up to $150 / \mathrm{min}$ lasting $70 \mathrm{~min}$ (Fig. 4B). Hyoscine $(10 \mu \mathrm{mol} / \mathrm{kg}$, i.p.) was then administered. Two intraventricular doses of muscarine each of 0.0067 now lacked effect on respiratory rate (Fig. 4B), electrocortical activity or posture. The lack of effect of muscarine after atropine or hyoscine was not due to development of tachyphylaxis as evident from Fig. 5, in which reproducible effects on electrocortical activity and respiration were obtained with two successive intraventricular doses of muscarine given $105 \mathrm{~min}$ apart. Despite the relative large dose of antagonists used, large amplitude slow frequency electrocortical activity observed in

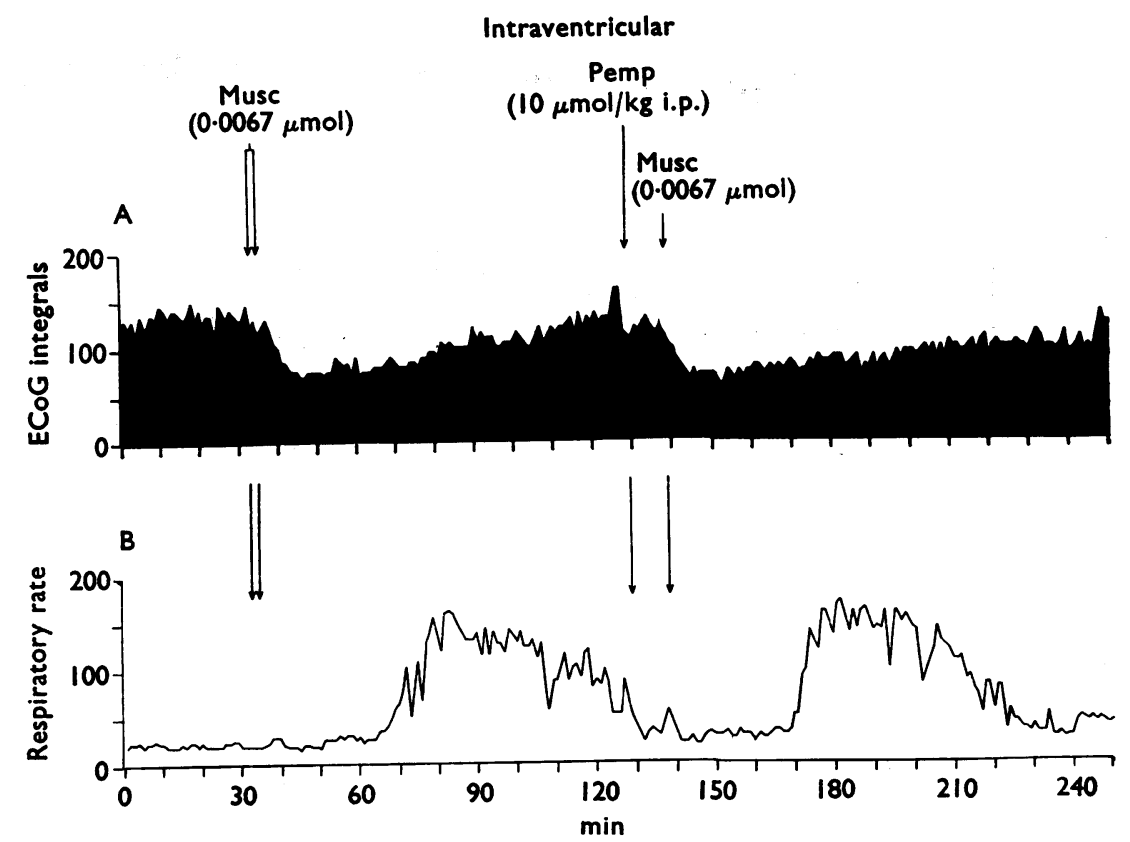

FIG. 5. Histogram of integrated electrocortical activity (A) and graph of respiratory rate (B) in an unanaesthetized, unrestrained adult fowl. Muscarine (0.0067 $\mu \mathrm{mol}$, intraventricularly) elicited electrocortical arousal together with reduction of electrocortical integrals and increased respiratory rate after a delay. The effects of a second similar dose of muscarine were unimpaired by the prior injection of pempidine $(10 \mu \mathrm{mol} / \mathrm{kg}, \mathrm{i} . \mathrm{p}$. $)$. 
mammals after atropine or hyoscine (Bradley \& Elkes, 1957) was not evoked in these experiments with fowls.

Similar doses of methylatropine (10 $\mu \mathrm{mol} / \mathrm{kg}$, i.p.) failed to prevent the electrocortical, respiratory and behavioural effects of muscarine. Methylatropine does not pass the blood-brain barrier, indicating that the muscarine effects were central in origin and not peripheral on account of its passage from the ventricle into the systemic vascular system. Pempidine also failed to antagonize the effects of muscarine. As shown in Fig. 5A, muscarine induced an almost immediate reduction in electrocortical integrals from $130-150 / \mathrm{min}$ to about $70 / \mathrm{min}$, associated with a change from the electrocortical drowsy to alert pattern. Tachypnoea developed $35 \mathrm{~min}$ after injection and persisted for $60 \mathrm{~min}$ (Fig. 5B). Pempidine $(10 \mu \mathrm{mol} / \mathrm{kg}$, i.p.) was then administered, which would provide a calculated antagonist to agonist ratio in the brain of $7 \cdot 5: 1$. Muscarine $(0.0067 \mu \mathrm{mol})$ was injected $10 \mathrm{~min}$ later but its effect on electrocortical integrals was not reduced (Fig. 5A), onset of tachypnoea was not delayed, nor was intensity of tachypnoea diminished although duration was slightly abbreviated (Fig. 5B).

\section{Anaesthetized fowls}

Respiration and blood pressure. Two fowls were tested. In contrast to results with non-anaesthetized fowls, muscarine given intraventricularly elicited only brief
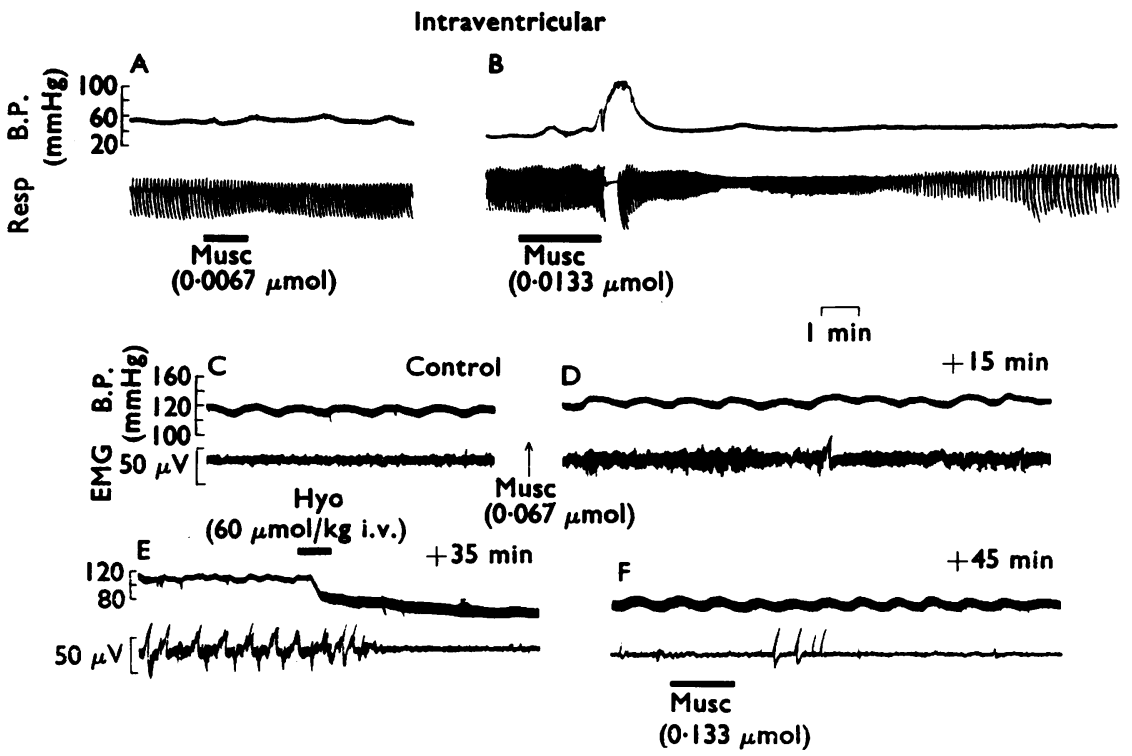

FIG. 6. Records of blood pressure and respiration $(A, B)$ in one fowl and blood pressure and electromyographic activity (C-F) respectively in a second fowl, both anaesthetized with chloralose. A complete upstroke and downstroke in the respiratory record corresponds to inspiration and expiration. Muscarine $(0.0067 \mu \mathrm{mol}$, intraventricularly) was ineffective on blood pressure and produced only slight diminution of respiratory amplitude. However, muscarine $(0.0133 \mu \mathrm{mol})$ raised blood pressure with recovery in 2 min associated with initial apnoea followed by diminution in respiratory amplitude for 11 minutes. C, Control blood pressure and electromyographic activity. D, Increased electromyographic potentials persisting $15 \mathrm{~min}$ after muscarine $(0.067 \mu \mathrm{mol}$, intraventricularly). E, Potentials associated with neck movements 35 min after muscarine. Intravenous hyoscine abolished these effects and diminished electromyographic activity. F, A larger dose of muscarine $(0.133 \mu \mathrm{mol}$, intraventricularly) was now without effect on electromyographic activity. In this and the following figure, the duration of injection is indicated by a bar. 
but immediate effects on respiration. As shown in Fig. 6A, muscarine $(0.0067$ $\mu \mathrm{mol})$ slightly diminished respiratory amplitude during injection, an effect complete within $2 \mathrm{~min}$; blood pressure was unaltered. With muscarine, $0.00133 \mu \mathrm{mol}$, respiration ceased for $30 \mathrm{~s}$, immediately after concluding intraventricular injection (Fig. 6B). When respiration recommenced, amplitude declined over the ensuing $3 \mathrm{~min}$ to about one-quarter that of the control and then gradually recovered. Mean ischiadic blood pressure rose from 40 to $110 \mathrm{mmHg}$ after the injection but had returned to preinjection values within $2 \mathrm{~min}$ of terminating injection. In the other fowl tested, intraventricular muscarine $(0.0033 \mu \mathrm{mol})$ elicited a fall followed by a rise in blood pressure.

Neck movements and electromyographic activity. Two fowls were tested. Larger intraventricular doses of muscarine than customarily given, for example $0.033 \mu \mathrm{mol}$, elicited strong neck movements. Control electromyographic activity $(10 \mu \mathrm{V})$ and blood pressure are shown in Fig. 6C. After intraventricular muscarine (0.067 $\mu \mathrm{mol})$ there was gradual and sustained increase of electromyographic potentials which 15 min later (Fig. 6D), were of $30 \mu \mathrm{V}$ amplitude. Thirty-five minutes after muscarine (Fig. 6E), the electromyogram consisted mostly of superimposed potentials coincident with repetitive side-to-side neck movements. These movement potentials were abolished (Fig. 6E) within $90 \mathrm{~s}$ by hyoscine $(60 \mu \mathrm{mol} / \mathrm{kg}$, i.v.). Muscarine $(0 \cdot 133$ $\mu \mathrm{mol}$ ) did not surmount antagonism (Fig. 6F).

\section{Intravenous muscarine}

These tests were done to ascertain whether the blood pressure effects of intraventricular muscarine were possibly due to passage of some of the drug from the brain into the systemic vascular system. Intravenous muscarine was expected to lower blood pressure, but as pressor effects were more marked than depressor, further investigations were made.

Of ten fowls tested, muscarine, in five, had initial depressor followed by pressor effects over the dose range used $(0.0033,0.0067,0.0133,0.026$ each in $\mu \mathrm{mol} / \mathrm{kg})$; in four, muscarine was pressor (Fig. 7A, B) ; in one, a small dose of muscarine (0.00166 $\mu \mathrm{mol} / \mathrm{kg}$, i.v.) had a depressor followed by a small pressor effect, but larger intravenous doses $(0.0033$ or $0.0066 \mu \mathrm{mol} / \mathrm{kg}$ in each) were entirely pressor. Rises in blood pressure were also obtained with intra-arterial muscarine. The effect could not be attributed to choline, the commonest contaminant of muscarine, for whereas muscarine $(0.0066 \mu \mathrm{mol} / \mathrm{kg}$, i.v.) raised mean ischiadic blood pressure a maximum of $105 \mathrm{mmHg}$ with return to basal pressure after $6 \mathrm{~min}$, intravenous choline in a 100 -fold greater dose $(0.66 \mu \mathrm{mol} / \mathrm{kg}$, i.v.) was ineffective on blood pressure.

In the next experiments, one hind limb of four fowls was perfused with arterial blood from the contralateral limb. In a dose ineffective on blood pressure, muscarine injected into the perfusion reservoir, that is, intra-arterially, lowered pressure in the perfused hind limb (Fig. 7H) an effect abolished by hyoscine. When blood pressure was initially lowered by intravenous muscarine, perfusion pressure usually fell (Fig. 7I) ; these falls were followed by rises in blood and perfusion pressures (Fig. 7I), that for blood pressure preceding that in perfusion pressure (Fig. 7J). Changes in perfusion pressure were not secondary to alterations of blood pressure since these were not transmitted to the perfused limb. Phenoxybenzamine (100 $\mu \mathrm{mol} / \mathrm{kg}$ injected into the perfusion reservoir) prevented these increases in blood and 
perfusion pressures, suggesting they were likely to be caused by circulating catecholamines secreted due to an action of muscarine on the suprarenal medullae.

Tests were therefore made in two fowls in which the suprarenal glands had been acutely removed so far as possible. Muscarine $(0.0033 \mu \mathrm{mol} / \mathrm{kg}$, i.v. $)$, which invariably raised blood pressure was now without effect, although a rise of $105 \mathrm{mmHg}$ was obtained with a 10 -fold larger dose $(0.0033 \mu \mathrm{mol} / \mathrm{kg}$, i.v.) presumably because of an action on residual medullary tissue. Evidence was next sought for a ganglionic action of muscarine in the fowl compatible with such an effect on the suprarenal medullae. Accordingly, a dose of pempidine $(2 \mu \mathrm{mol} / \mathrm{kg}$, i.v.) was administered sufficient to abolish the pressor effects of nicotine, $0.2 \mu \mathrm{mol} / \mathrm{kg}$, i.v. (compare Fig. $7 \mathrm{C}$ with D). This dose prevented the pressor effect of muscarine $(0.0033 \mu \mathrm{mol} / \mathrm{kg}$, i.v.) (Fig. 7E), although antagonism was surmounted by muscarine $(0.033 \mu \mathrm{mol} / \mathrm{kg}$, i.v.) (Fig. 7F), an effect unaltered by hyoscine $(2 \mu \mathrm{mol} / \mathrm{kg}$, i.v.) (Fig. 7G).

\section{Intracerebral microinfusion}

A total of thirty-two experiments were performed in twenty-five 12-21 day chicks. Electrocortical arousal was obtained but effects on behaviour depended on site of infusion.
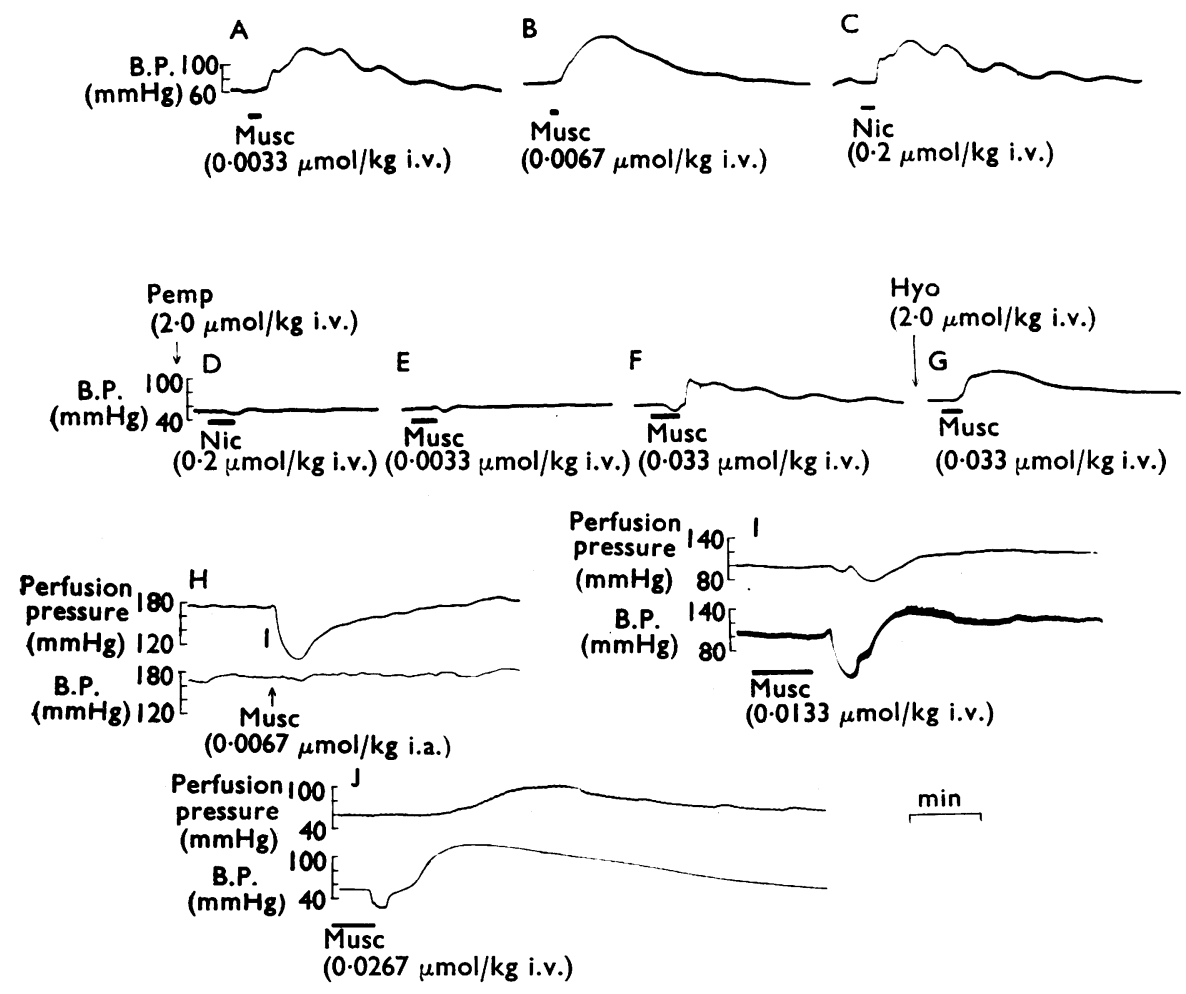

FIG. 7. Records of blood pressure (A-G) in one fowl and perfusion and blood pressures (H-J) in a second fowl, both anaesthetized with chloralose. A, B, C, Control blood pressure responses to intravenous muscarine or nicotine. $D$ and $E$, Effects of intravenous nicotine and muscarine abolished by prior intravenous dose of pempidine. F, Antagonism by pempidine surmounted with muscarine $(0.033 \mu \mathrm{mol} / \mathrm{kg}$, i.v.) but $(G)$ not antagonized by intravenous hyoscine. H, Muscarine $(0.0067 \mu \mathrm{mol} / \mathrm{kg})$ injected intra-arterially to the perfused limb lowers perfusion but not blood pressure. However, intravenous doses of muscarine (I, J) while initially lowering blood pressure, thereafter increase perfusion and blood pressures. 
Infusion into the diencephalon. Electrocortical effects of muscarine $(0.0033$ $\mu \mathrm{mol})$ microinfused into the hypothalamus are shown in Fig. 8. Before injection the 15-day chick was drowsy or asleep, with large amplitude $(100-200 \mu \mathrm{V}), 6-10 \mathrm{~Hz}$ potentials (Fig. 8A), associated with integrals ranging between 120 and $230 / \mathrm{min}$ (Fig. 8D). Muscarine $(0.0033 \mu \mathrm{mol})$ induced immediate bilateral electrocortical alerting, potentials falling to $10-20 \mu \mathrm{V}$ amplitude and containing small $8-10 \mathrm{~Hz}$

Hypothalamic

A

Minute

integral

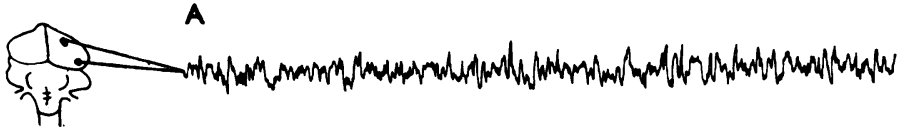

183

B

Acum

C

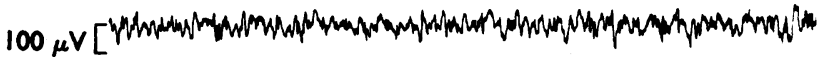
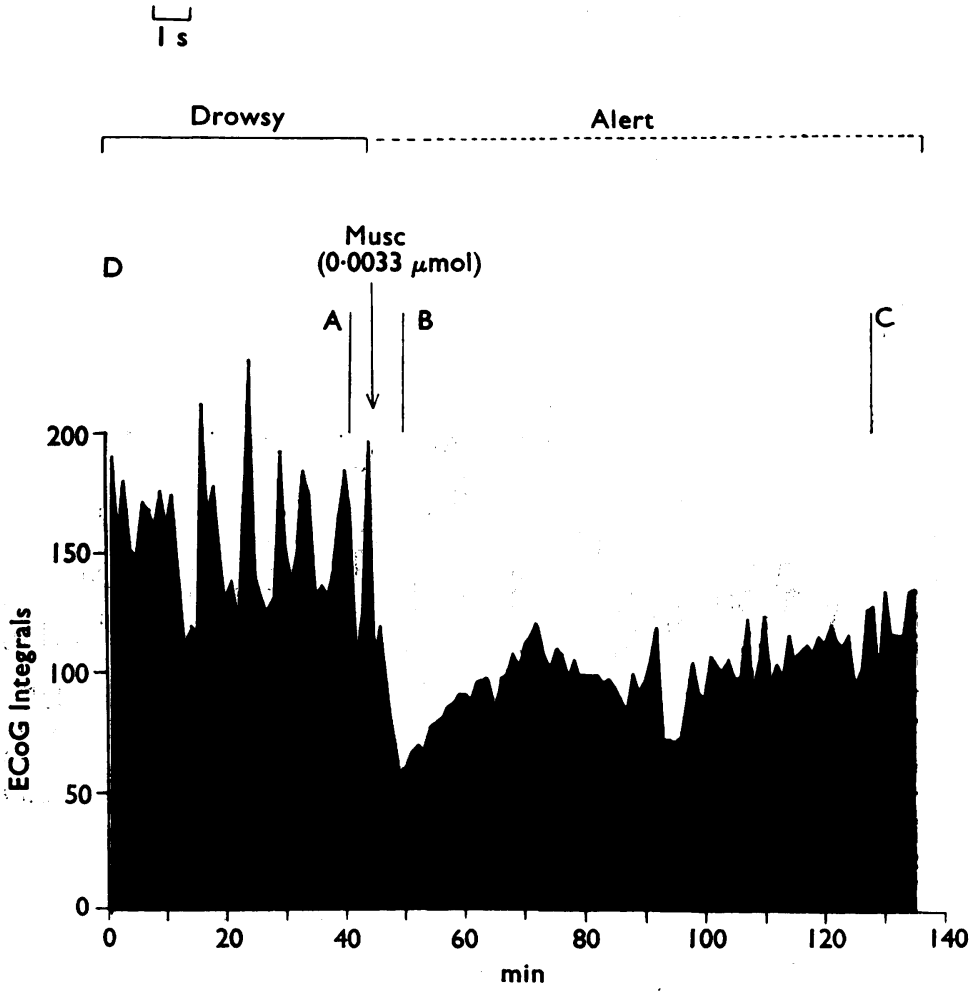

FIG. 8. Records of electrocortical activity (A-C) and histogram of integrated electrocortical activity (D) in an unanaesthetized, unrestrained 13-day chick. Epochs corresponding to A, B and $\mathrm{C}$ are indicated in the histogram and integrals for the corresponding minute of electrocortical activity are given on the right of the trace. A, Control drowsy electrocortical activity. B, Electrocortical arousal accompanied by reduction in electrocortical integrals after microinfusion of muscarine into the hypothalamus; electrocortical arousal extended to both hemispheres. C, Return of drowsy activity in the electrocorticogram. 
components superimposed on faster frequency potentials (Fig. 8B). Electrocortical integrals declined to $60 / \mathrm{min}$ (Fig. $8 \mathrm{D}$ ), recovering over the ensuing $85 \mathrm{~min}$ to $110-135 / \mathrm{min}$ with return of larger amplitude potentials (Fig. 8C). Alternating bouts of quiescence and violent motor activity, including 'escape' leaping movements, accompanied electrocortical arousal. Postural and respiratory phenomena, observed with intraventricular injections, did not develop. Body temperature was unaffected, environmental temperature $\left(29^{\circ}-31^{\circ}\right.$ C) being thermoneutral.

Infusion into the telencephalon. The effects of muscarine differed from those obtained with infusions into the hypothalamus, electrocortical arousal being confined to the ipsilateral cerebral hemisphere and behavioural arousal absent. The

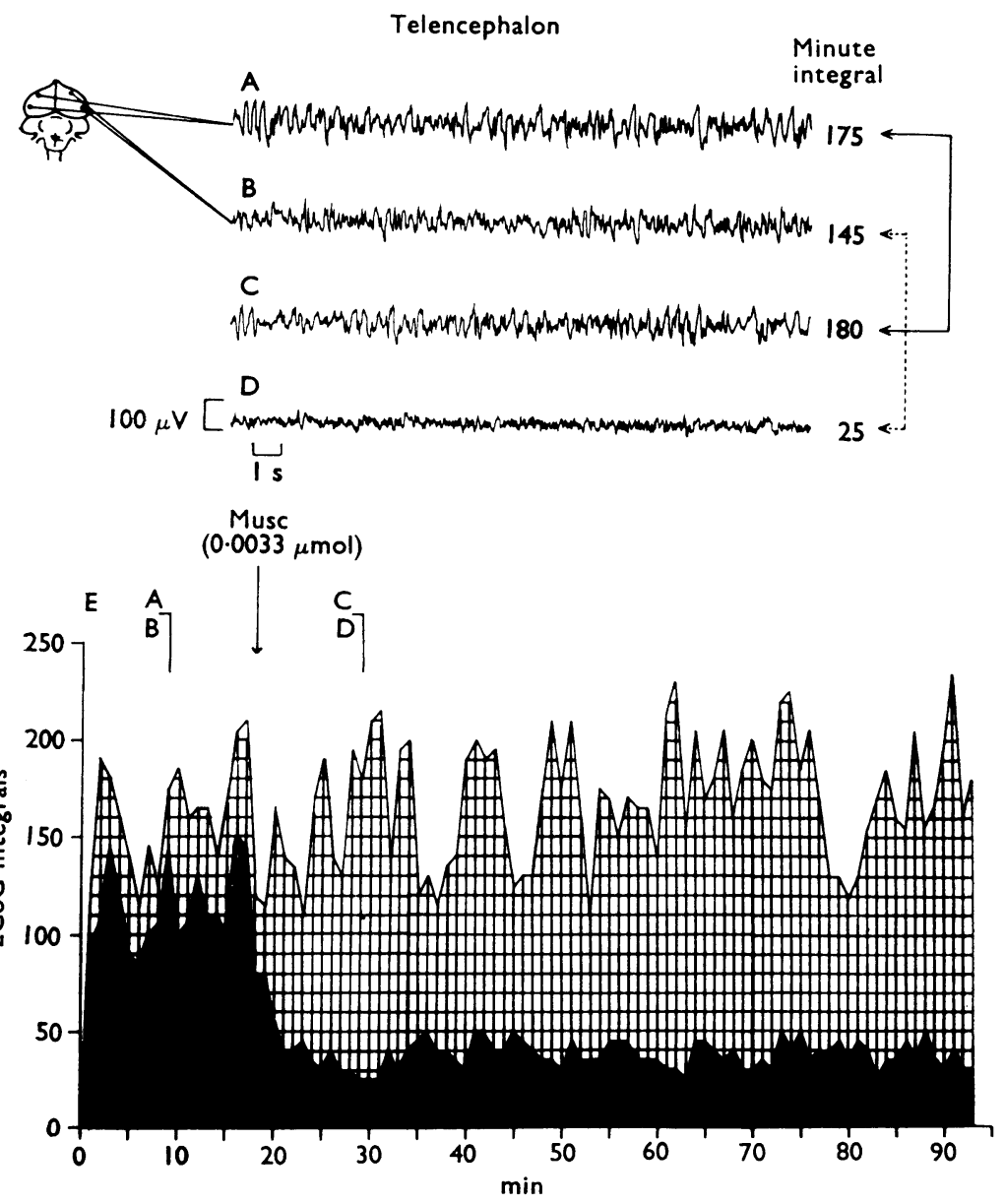

FIG. 9. Records of electrocortical activity (A-D) and histograms of integrated electrocortical activity $(E)$ in an unanaesthetized, unrestrained 13-day chick. A, C are records from the left cerebral hemisphere; B, D are records from the right cerebral hemisphere. Hatched areas in E represent integrated electrocortical activity from the left cerebral hemisphere; solid areas represent integrated electrocortical activity from right cerebral hemisphere. Epochs corresponding to $\mathbf{A}, \mathbf{B}, \mathbf{C}$ and $\mathrm{D}$ are indicated in the histograms and integrals for the corresponding minute of electrocortical activity are given on the right of the traces. $\mathrm{A}$, B, Control drowsy electrocortical activity. D, E, Electrocortical arousal with reduction of electrocortical integrals from right cerebral hemisphere after microinfusion of muscarine into the right telencephalon. C, E, Electrocortical activity and electrocortical integrals from left cerebral hemisphere were unaltered by muscarine. 
effects on electrocortical activity are shown in Fig. 9, tracings taken from a chick with the infusion cannula implanted with its tip just anterior to the anterior commissure and medial to the lateral forebrain bundle. Muscarine $(0.0033 \mu \mathrm{mol}) \mathrm{micro}-$ infused into the right cerebral hemisphere induced ipsilateral electrocortical arousal, the large amplitude $(60-125 \mu \mathrm{V})$ slow frequency $(5-8 \mathrm{~Hz})$ potentials (Fig. 9B) changing to $30 \mu \mathrm{V}, 10-15 \mathrm{~Hz}$ activity (Fig. 9D). This effect developed within $4 \mathrm{~min}$ of infusion and remained as intense for the ensuing $75 \mathrm{~min}$ of the experiment. Electrocortical alerting was accompanied by reduction in integrals from a control of 90-150/min to $25-50 / \mathrm{min}$ (Fig. 9E). In contrast, electrocortical activity recorded from the contralateral hemisphere (Fig. 9A, C) was unchanged as were electrocortical integrals (Fig. 9E).

Infusion into the myelencephalon. The effects of muscarine microinfused into the brain-stem resembled those after diencephalic infusion save that arousal was frequently more intense. For example, in a 13-day chick, drowsy during the control period with large amplitude $(80-200 \mu \mathrm{V})$ slow frequency $(6-8 \mathrm{~Hz})$ electrocortical potentials associated with integrals of $140-210 / \mathrm{min}$, muscarine $(0.0033 \mu \mathrm{mol})$, induced immediate behavioural and bilateral electrocortical arousal with correspondingly small electrocortical integrals $(55-65 / \mathrm{min})$; the cannula tip lay near the dorsomedial oculomotor nucleus. Electrocortical activity and integrals reverted over the ensuing $90 \mathrm{~min}$ to the control pattern.

Antagonism. The effects of muscarine on behaviour and electrocortical activity were antagonized by hyoscine given intravenously or locally into the site of infusion. Figure 10A, B, depicts histograms of electrocortical activity obtained from two drowsy chicks. In the first, muscarine $(0.0033 \mu \mathrm{mol})$ was microinfused into the hypothalamus, after hyoscine (10 $\mu \mathrm{mol} / 100 \mathrm{~g}$, i.v.), which would give a ratio for antagonist to agonist of $46: 1$ in the brain. This and an ensuing similar dose of muscarine, did not produce electrocortical alerting and there was no change in electrocortical integrals. In the other chick and in contrast (Fig. 10B), after pempidine $(10 \mu \mathrm{mol} / 100 \mathrm{~g}$, i.v. $)$ muscarine elicited immediate electrocortical arousal, electrocortical integrals falling from a control of $130-250 / \mathrm{min}$ to $70-105 / \mathrm{min}$ after the injection and for the following $60 \mathrm{~min}$; integrals increased to $150 / \mathrm{min}$ by the end of the experiment. Electrocortical alerting accompanied behavioural arousal.

Whereas hyoscine given first readily prevented the effects of muscarine, once the effects of muscarine were established, antagonism with hyoscine was difficult to achieve. Thus muscarine $(0.0033 \mu \mathrm{mol})$ produced electrocortical and behavioural arousal in a drowsy chick, electrocortical integrals declining from $100-175 / \mathrm{min}$ to 45-55/min (Fig. 10C). Restoration of control electrocortical activity and integrals was only obtained after three spaced doses of hyoscine, each of $10 \mu \mathrm{mol} / \mathrm{kg}$, intravenously. The alert chick gradually became drowsy and two subsequent doses of muscarine (each of $0.0033 \mu \mathrm{mol}$ ) were now without effect on behaviour or electrocortical activity.

More important, similar antagonistic effects were obtained with hyoscine when microinfused into the same region of the brain as muscarine. As shown in Fig. $11 \mathrm{~A}$, integrals of electrocortical activity from a drowsy chick, infusion into the hypothalamus of muscarine $(0.0033 \mu \mathrm{mol})$-a dose that elicits electrocortical arousal (Figs. 8B, D)-was ineffective $21 \mathrm{~min}$ after hyoscine $(0 \cdot 1 \mu \mathrm{mol})$ infused into the same site. In contrast, in another drowsy chicken, muscarine $(0.0033 \mu \mathrm{mol})$ microinfused into the hypothalamus first, evoked electrocortical arousal, represented in Fig. 11B 

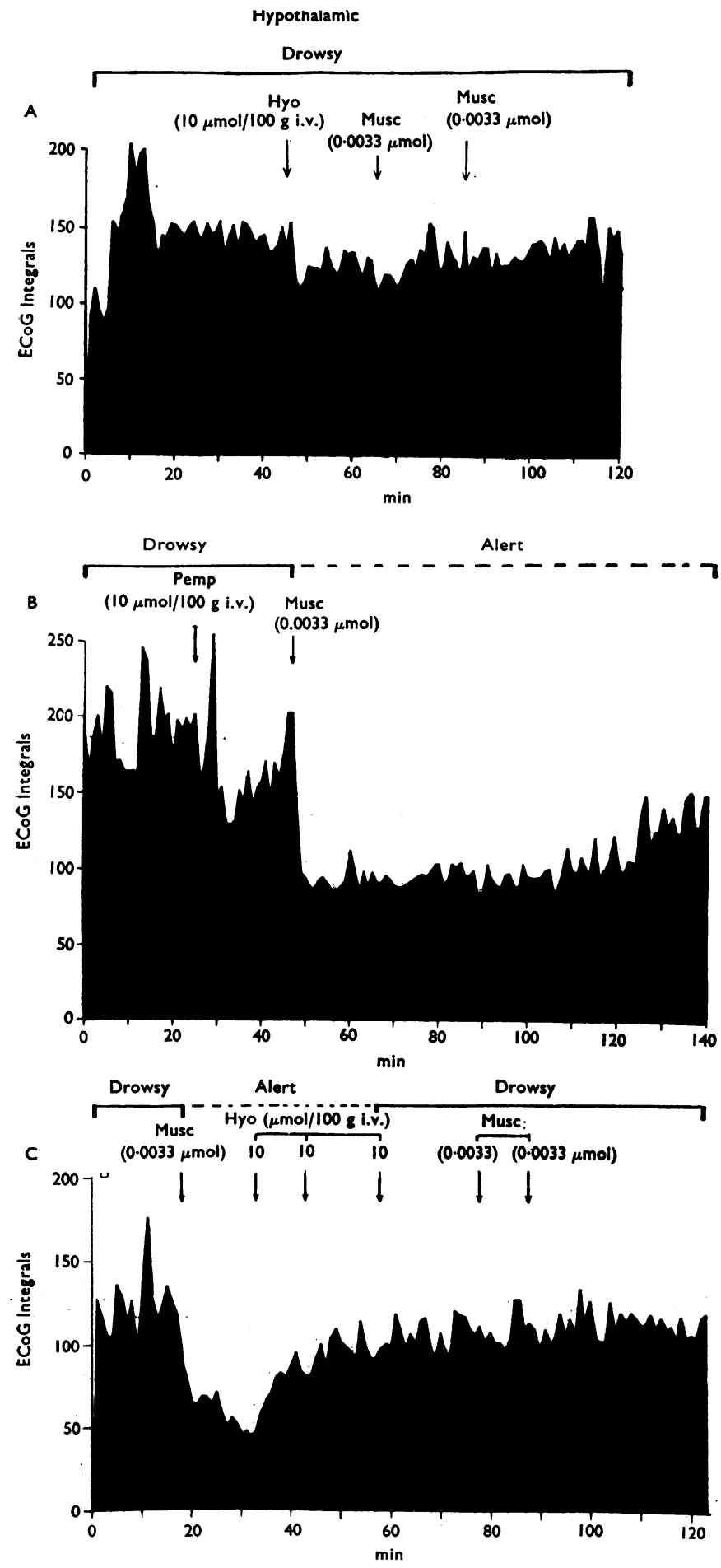

FIG. 10. Histograms of integrated electrocortical activity from three unanaesthetized, unrestrained drowsy chicks of 13 (A) and 14 (B, C) days. In A, hyoscine $(10 \mu \mathrm{mol} / 100 \mathrm{~g}$, i.v.) prevents electrocortical arousal and associated reduction of electrocortical integrals after two microinfusions of muscarine each of $0.0033 \mu \mathrm{mol}$ into the hypothalamus, whereas (B) electrocortical arousal and reduction of electrocortical integrals with microinfusion of muscarine $(0.0033 \mu \mathrm{mol})$ into this site is not prevented by a similar intravenous dose of pempidine. In $\mathrm{C}$, electrocortical arousal elicited by muscarine $(0.0033 \mu \mathrm{mol})$ infused into the hypothalamus was attenuated by three separate doses of hyoscine (each of $10 \mu \mathrm{mol} / \mathrm{kg}$, i.v.). Two subsequent microinfusions each of muscarine, $0.0033 \mu \mathrm{mol}$ were now without effect on electrocortical antivity or hehavinur. 
by reduction in electrocortical integrals, accompanied by behavioural alerting. Hyoscine microinfused in a larger dose $(0.15 \mu \mathrm{mol})$ than that preventing arousal with muscarine in the experiment of Fig. 11A, did not attenuate behavioural arousal, although the electrocortical pattern became less alert with some increase in electrocortical integrals.
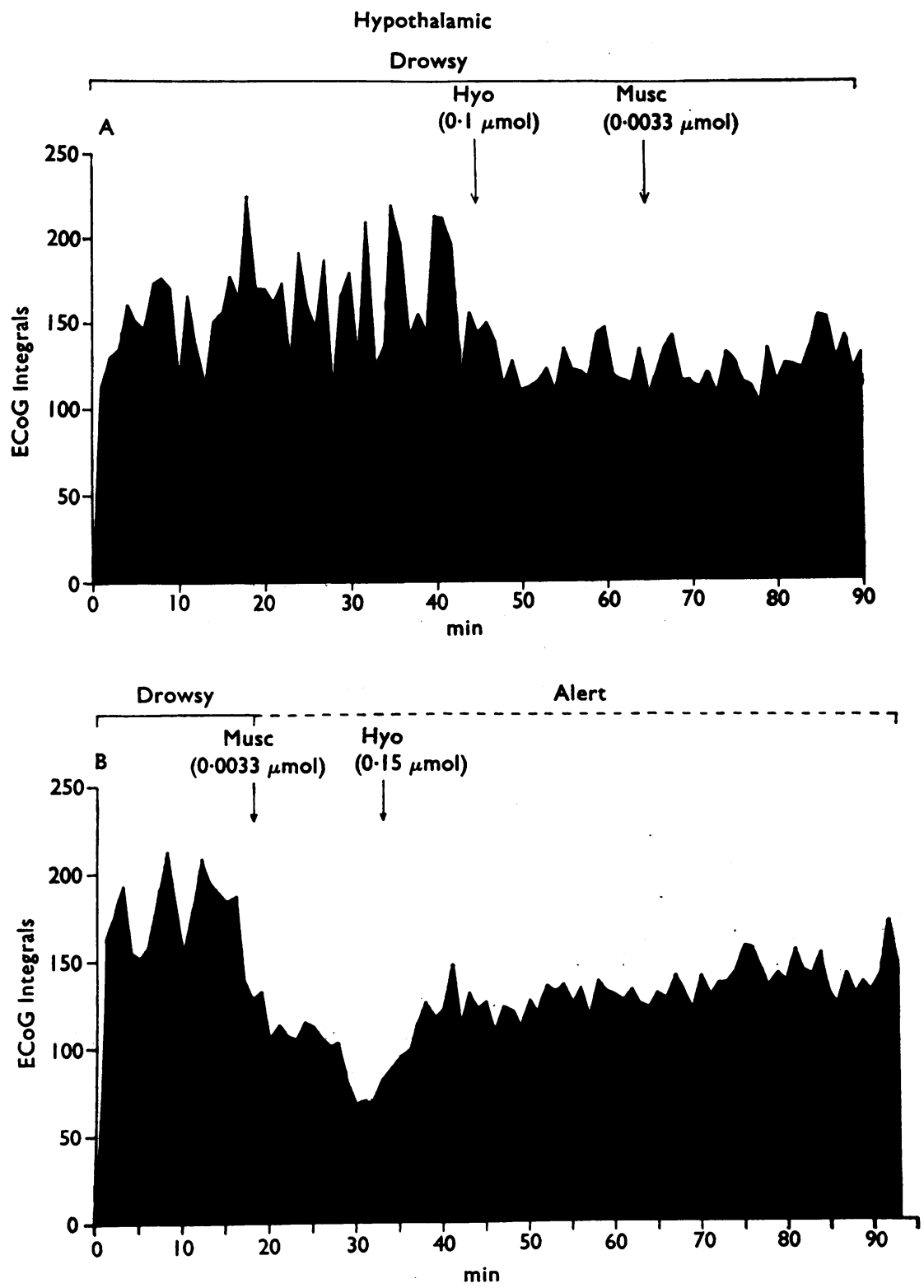

FIG. 11. Histograms of integrated electrocortical activity from two unanaesthetized, unrestrained drowsy chicks, both 15 days. A, Microinfusion of hyoscine $(0: 1 \mu \mathrm{mol})$ into the hypothalamus before muscarine, microinfused into the same site, prevents electrocortical arousal, whereas (B) once electrocortical arousal was established with muscarine infused into the hypothalamus, a larger dose of hyoscine $(0 \cdot 15 \mu \mathrm{mol})$, microinfused into the same site, only partially antagonized arousal. 


\section{Discussion}

There are few studies with muscarine, particularly after intracerebral administration, on behaviour and electrocortical activity of mammals and apparently none hitherto in fowls. This discussion is mainly confined to experiments in which drugs were administered into the brain.

In the present investigation with fowls, muscarine given into the IIIrd ventricle or microinfused into the brain elicited behavioural and electrocortical arousal. Muscarinic drugs, arecoline, pilocarpine and oxotremorine, given intravenously to 7-day chicks (Leslie, 1965) also had excitant effects, likened to those of amphetamine, that is 'spreading of wings, feather erection, cheeping and increased ambulation followed by ataxia'. The marked action of cholinomimetic drugs on skeletal musculature after intravenous injection, could account for differences between our observations and those of Leslie.

Muscarine and carbachol applied to the hypothalamus of rats, increased operant responding for food and water (Stein \& Seifter, 1962). In cats, muscarinic drugs given into the brain elicited effects ranging from overactivity to stupor, making comparison with results in fowls difficult. Thus intraventricular carbachol or pilocarpine elicited rage, piloerection, hissing and unsheathing of claws (Borison, 1959; Leslie, 1965 ; MacLean, 1957). However, Myers (1964) observed stupor in cats after intraventricular carbachol, although carbachol infused into the hypothalamus elicited fear, growling, spitting, rage and attack. Hernández-Peón, Chávez-Ibarra, Morgane \& Timo-Iaria (1963) induced sleep in cats by applying carbachol adjacent to the medial forebrain bundle from the 'limbic' forebrain to midbrain, whereas application more dorsally evoked alertness. These last findings were contested by Macphail \& Miller (1968) who infused carbachol into the same brain areas, eliciting solely 'affective defence reactions'-growling, hissing, piloerection, mydriasis, flattening of the ears, but not sleep. Arousal with muscarine in fowls lacked apparent affective components, possibly because there was no appropriate eliciting stimulus.

Electrocortical arousal was obtained in feline encéphale isolé preparations with intravenous muscarine (Riehl \& Unna, 1960) or tremorine (Baker, Hosko, Rutt \& McGrath, 1960). Behavioural and electrocortical alerting were evoked by carbachol microinfused into the preoptic region of rats (Macphail, 1968) and by intravenous pilocarpine or arecoline into the same region of cats (Domino, Yamamoto \& Drew, 1968). Small intravenous doses of physostigmine or diisopropylfluorophosphate abolished the sleep electrocortical pattern of intact cats replacing it with one of alert activity without inducing behavioural arousal (Bradley \& Elkes, 1957); similar effects were obtained with physostigmine in cat and monkey encéphale isolé preparations.

The delay before tachypnoea developed after intraventricular muscarine, a quaternary substance, was presumably ascribable to difficulty of penetration to sites of action some distance from the fowl's IIIrd ventricle; it was unlikely to be due to formation of active metabolites, muscarine being stable in vivo (Fraser, 1957). Sites mediating electrocortical effects were apparently close to the ventricular space, since electrocortical alerting developed almost at once. Although panting was accompanied by postural changes similar to those observed with fowls in environments above thermoneutrality—or following drugs which raise body temperature, tempera- 
ture was unaffected by muscarine given intraventricularly or into the hypothalamus. The respiratory heat loss during panting could, however, have compensated for an increased heat production, temperature therefore remaining unaltered. In contrast, with chloralosed fowls, intraventricular muscarine briefly diminished respiratory rate and amplitude. Panting developed in cats after intraventricular pilocarpine (Borison, 1959) or after carbachol microinjected into the hypothalamus (Macphail \& Miller, 1968).

Muscarine and nicotine injected intraventricularly in chloralosed fowls raised blood pressure (Marley \& Seller, 1970a, b). In rats, muscarine, methacholine or oxotremorine injected into the hypothalamus lowered blood pressure followed, in half the animals, by an increase in pressure (Brezenoff \& Wirecki, 1970).

In rabbits, cats and dogs, intravenous muscarine or acetylcholine lowered blood pressure, effects abolished by atropine (Fraser, 1957). The pressor effect in fowls of intravenous muscarine, although unexpected, was not due to an intrinsic vasoconstrictor action, since injected intra-arterially to the perfused hind limb, muscarine lowered perfusion pressure. The rise in blood pressure could be attributed to several factors, one of which was secretion of adrenal medullary catecholamines since the pressor effects were considerably reduced after extirpating the suprarenal glands. In cats, muscarinic drugs, for example, pilocarpine (Dale \& Laidlaw, 1912) and carbachol (Butterworth \& Mann, 1958) liberate adrenal medullary catecholamines. Another possibility was excitation of autonomic ganglia from which sympathetic vasoconstrictor nerves derive.

The effects of muscarine on behaviour, posture, respiration and electrocortical activity were prevented by atropine or hyoscine given intravenously or locally into the brain but not by pempidine or mecamylamine. The exception was the pressor response to intravenous muscarine, abolished by pempidine. Cholinoceptive sites of ganglia include those sensitive to atropine, curare and ganglion-blocking agents (Volle, 1966). For example, muscarine injected directly to the perfused superior cervical ganglion of cats, contracted the ipsilateral nictitating membrane, a response abolished by infusion of atropine, nicotine or hexamethonium to the ganglion (Ambache, Perry \& Robertson, 1956). The adrenal medulla, ancestral homologue of ganglia, also has cholinoceptive sites sensitive to different antagonists.

Since arousal was obtained by application of muscarine to the brainstem, hypothalamus, thalamus and structures bordering the intraventricular space, these must be connected by a cholinoceptive arousal system. This muscarine sensitive system is apparently solely afferent in the forebrain, electrocortical alerting being confined to the ipsilateral cerebral hemisphere after microinfusion of muscarine into that side of the telencephalon. In contrast, unilateral infusions into and posterior to the hypothalamus elicited behavioural and bilateral electrocortical alerting. The lateral forebrain bundle and cortico-septo-mesencephalic tracts connect the telencephalon with lower centres (Kappers, Huber \& Crosby, 1936); the latter tract is reputedly efferent while the former, though providing the principal efferent tracts from the striatum (Jones \& Levi-Montalcini, 1958) also includes three afferent tracts. Two originate from the thalamic nuclei, and the third from the tectum; all terminate in the telencephalon. These tracts, of multiple origin, may also be multisynaptic since muscarine elicited arousal from so many sites; by the same token, the tracts must terminate diffusely for muscarine to have such widespread effects. A multisynaptic nature of the tracts is compatible with the arrangement of the many inter-linked 
nuclei forming the striatal complex of the chicken brain. The widespread distribution of receptors mediating the effects of muscarine, contrasts with the restricted nature of those for catecholamines, the effects of which were elicited by microinfusion into the hypothalamus, and no other region tested, of the chicken's brain (Marley \& Stephenson, 1968, 1970).

Irrespective of species, the notion of a cholinergic arousal system is generally less accepted than that of an adrenergic one. Certainly, amphetamine-like drugs induce behavioural and electrocortical alerting in chickens, effects which are not attenuated or prevented by hyoscine (Dewhurst \& Marley, 1965a, b) and which are mediated via sites extending anteriorly through the diencephalon into the posterior paleostriatum (Marley \& Stephenson, 1971). The cholinergic arousal system differs therefore in its pharmacological characteristics from that sensitive to amphetamine-like amines. Apart from responsiveness to muscarine or muscarinic drugs, there are histochemical grounds for assuming such a system in fowls and mammals. Thus, cholinesterase has a widespread uniform distribution in the chicken nervous system (Cavanagh \& Holland, 1961) and choline acetylase is present in the optic lobes and cerebrum (Hebb, 1955). Shute \& Lewis $(1966,1967)$ demonstrated choline acetylase and cholinesterase in cat and rat brain neurones; the arousal system consisted of a series of inter-connected neurones which were cholinoceptive as well as cholinomimetic.

The existence of two arousal systems poses certain questions. The cholinergic system can be linked with the presence of acetylcholine in the brain. The amphetamine-like amines are, however, synthetic, and their action is ascribable to their mimicking or releasing a natural transmitter. Amphetamine significantly augmented the amount of acetylcholine released from the rabbit's parietal cortex (Beani, Bianchi, Santinoceto \& Marchetti, 1968), an effect ascribed to its action on reticulocortical cholinergic pathways. Should amphetamine, directly or indirectly, increase the amount of acetylcholine released from cholinergic fibres in the chicken brain, this would contribute to its alerting effect. Certainly, N-methylamphetamine enhanced choline acetyltransferase activity of the optic lobes of chicks (Mandell \& Knapp, 1971), suggesting that acetylcholine synthesis was augmented. While acetylcholine may mediate some of amphetamine's central effects, this is only part explanation, behavioural and electrocortical alerting evoked by amphetamine being resistant to hyoscine in fowls.

The presence of, and presumably need for, two arousal systems is an intriguing conundrum and can be expeditiously used as argument for biological expediency or profligacy.

This work was supported by grants from the Tobacco Research Council and the Bethlem Royal and Maudsley Hospitals Research Fund, which we gratefully acknowledge. Our thanks are due to Mrs. V. J. Eley for the histological preparations and to Mrs. D. F. Wilkinson for typing the manuscript. We are indebted to Geigy Pharmaceuticals for muscarine, Imperial Chemical Industries for Fluothane and pempidine and to Merck, Sharp \& Dohme Ltd. for mecamylamine.

\section{REFERENCES}

Allen, D. J. \& Marley, E. (1967). Effect of sympathomimetic and allied amines on temperature and oxygen consumption in chickens. Br.J. Pharmac. Chemother., 31, 290-312.

Ambache, N., Perry, W. L. M. \& Robertson, P. A. (1956). The effect of muscarine on perfused superior cervical ganglia of cats. Br.J. Pharmac. Chemother., 11, 442-448.

Baker, W. W., Hosko, M. J., RuTt, W. J. \& MCGrath, J. R. (1960). Tremorine-induced rage and its antagonism by atropine. Proc. Soc. exp. Biol., 104, 214-217. 
Beani, L., Bianchi, C., Santinoceto, L. \& Marchetti, P. (1968). The cerebral acetylcholine release in conscious rabbits with semi-permanently implanted epidural cups. Int. J. Neuropharmac., 7, 469-481.

BorisON, H. L. (1959). Effect of ablation of medullary emetic chemoreceptor trigger zone on vomiting responses to cerebral intraventricular injection of adrenaline, apomorphine and pilocarpine in the cat. J. Physiol., Lond., 147, 172-177.

Bradley, P. B. \& ElKeS, J. (1957). The effect of some drugs on the electrical activity of the brain. Brain, 80, 77-117.

Bradley, P. B., Dhawan, B. N. \& Wolstencroft, J. H. (1966). Pharmacological properties of cholinoceptive neurones in the medulla and pons of the cat. J. Physiol., Lond., 183, 658-674.

BREZENOFF, H. E. \& WIRECKI, T. S. (1970). The pharmacological specificity of muscarinic receptors in the posterior hypothalamus of the rat. Life Sci., Oxford, 9, 99-109.

Butterworth, K. R. \& MANN, M. (1958). The effect of various choline esters on the adrenal gland of the cat. J. Pharm. Pharmac., 10, 295-301.

Calder, W. A. \& Schmidt-Nielsen, K. (1968). Panting and blood carbon dioxide in birds. Am. J. Physiol., 25, 477-482.

Cavanagh, J. B. \& Holland, P. (1961). Cholinesterase in the chicken nervous system. Nature, Lond., 190, 735-736.

Dale, H. H. (1914). The action of certain esters and ethers of choline and their relation to muscarine. J. Pharmac. exp. Ther., 6, 147-190.

Dale, H. H. \& Laidlaw, P. P. (1912). Some actions of pilocarpine and nicotine. J. Physiol., Lond., 44, xii-xiii $P$.

Dewhurst, W. G. \& Marley, E. (1965a). The effects of $\alpha$-methyl derivatives of noradrenaline, phenethylamine and tryptamine on the central nervous system of the chicken. Br. J. Pharmac. Chemother., 25, 682-704.

Dewhurst, W. G. \& Marley, E. (1965b). Action of sympathomimetic and allied amines on the central nervous system of the chicken. Br. J. Pharmac. Chemother., 25, 705-727.

Domino, E. F., Y амamoto, K. \& DREw, A. T. (1968). Role of cholinergic mechanisms in states of wakefulness and sleep. In: Progress in Brain Research, ed. Bradley, P. B. \& Fink, M., vol. 28, pp. 113-133, Amsterdam: Elsevier.

Fraser, P. J. (1957). Pharmacological actions of pure muscarine chloride. Br. J. Pharmac. Chemother., 12, 47-52.

Grunden, L. R. \& MARLEY, E. (1970). Effects of sympathomimetic amines injected into the third ventricle in adult chickens. Neuropharmacology, 9, 119-128.

Hebв, C. O. (1955). Choline acetylase in mammalian and avian sensory systems. Q. J. exp. Physiol., 40, $176-186$.

Hernández-Peón, R., Chávez-Ibarra, G., Morgane, P. T. \& Timo-Iaria, C. (1963). Limbic cholinergic pathways involved in sleep and emotional behaviour. Exp. Neurol., 8, 93-111.

INMAN, O. R. (1968). Nongraded dehydration and low pressure infiltration for rapid celloidin embedding of brain tissue. Stain Tech., 43, 69-74.

Jones, A. W. \& Levi-Montalcini, R. (1958). Patterns of differentiation of the nerve centres and fibre tracts in the avian cerebral hemispheres. Archs ital. Biol., 96, 231-284.

Kappers, C. V. A., Huber, G. C. \& Crosby, E. C. (1936). The Comparative Anatomy of the Nervous System of the Vertebrates including Man, pp. 1013-1061 and 1358-1401. New York: Hafner.

KeY, B. J. \& MARLEY, E. (1962). The effect of the sympathomimetic amines on behaviour and electrocortical activity of the chicken. Electroenceph. clin. Neurophysiol., 14, 90-105.

KRnjević, K. \& Phillis, J. W. (1963). Pharmacological properties of acetylcholine sensitive cells in the cerebral cortex. J. Physiol., Lond., 166, 328-350.

LeSLIE, G. B. (1965). Central stimulant properties of compounds with peripheral muscarinic properties. Nature, Lond., 208, 1291-1293.

MacLean, P. D. (1957). Chemical and electrical stimulation of hippocampus in unrestrained animals. II. Behavioural findings. Archs Neurol. Psychiat., 78, 128-142.

MacPhaIL, E. M. (1968). Effects of intracranial cholinergic stimulation in rats on drinking, EEG and heart rate. J. comp. Physiol. Psychol., 65, 42-49.

MacPhail, E. M. \& Miller, N. E. (1968). Cholinergic brain stimulation in cats: failure to obtain sleep. J. comp. Physiol. Psychol., 65, 499-503.

MaNDELl, A. J. \& KNAPP, S. (1971). The effects of chronic administration of some cholinergic and adrenergic drugs on the activity of choline acetyltransferase in the optic lobes of the chick brain. Neuropharmacology, 10, 513-516.

MARley, E. \& PAYNe, J. P. (1964). Halothane anaesthesia in the fowl. In: Small Animal Anaesthesia, pp. 127-134. Oxford: Pergamon Press.

MARLeY, E. \& Seller, T. J. (1970a). Some effects of muscarine on the central nervous system of chickens. Br. J. Pharmac., 40, 139-140P.

Marley, E. \& Seller, T. J. (1970b). Some effects of nicotine on the central nervous system of chickens. Br. J. Pharmac., 40, 141-142P.

MARley, E. \& StePhenson, J. D. (1968). Intracerebral micro-infusions of drugs under controlled conditions in young chickens. J. Physiol., Lond., 196, 97-99P. 
MARLEy, E. \& STEPHENSON, J. D. (1970). Effects of catecholamines infused into the brain of young chickens. Br. J. Pharmac., 40, 639-658.

MARLeY, E. \& Stephenson, J. D. (1971). Actions of dexamphetamine and amphetamine-like amines in chickens with brain transections. Br.J. Pharmac., 42, 522-542.

MYERS, R. D. (1964). Emotional and autonomic responses following hypothalamic chemical stimulation. Can. J. Psychol., 18, 6-14.

RIEHL, J. L. \& UNNA, K. R. (1960). Effects of muscarine on the central nervous system. In: Recent Advances in Biological Psychiatry, ed. Wortis. J., pp. 345-361. New York: Grune \& Stratton.

SAXBY, O. B., SidDioI, S. \& WALKER, J. M. (1960). Continuous superfusion by means of a simple roller pump. J. Physiol., Lond., 153, 6-7P.

Shute, C. C. D. \& Lewis, P. R. (1966). Cholinergic and monoaminergic pathways in the hypothalamus. Br. med. Bull., 22, 221-226.

SHUTE, C. C. D. \& LEWIs, P. R. (1967). The ascending reticular system: Neocortical, olfactory and subcortical projections. Brain, 90, 497-517.

Stein, L. \& Seifter, J. (1962). Muscarinic synapses in the hypothalamus. Am. J. Physiol., 202, 751-756.

Stephenson, J. D. (1969). Actions of sympathomimetic and allied amines on the avian central nervous system. Ph.D. thesis, University of London.

Volle, R. L. (1966). Modification by drugs of synaptic mechanisms in autonomic ganglia. Pharmac. Rev. 18, 839-869.

(Received June 16, 1971) 